\title{
CONTRIBUIÇÕES PARA O PLANEJAMENTO DE PARQUES TECNOLÓGICOS URBANOS
}

Desirée Moraes Zouain ${ }^{1}$

\section{INTRODUÇÃO}

O fenômeno da globalização dos mercados, que vem se desenvolvendo de forma acelerada, introduz novas demandas e desafios com relação a políticas e a mecanismos que promovam a geração e a disseminação do conhecimento como base para a competitividade empresarial e o crescimento econômico (Albagli, 1999; Cassiolato \& Lastres, 1999; Salomão, 1998; Terra, 2000).

Dentre esses mecanismos, encontram-se sistemas e formas de cooperação que visam o estabelecimento de relações profícuas e duradouras entre as universidades e instituições de pesquisa com o setor empresarial, permitindo sua constante renovação e capacitação para a competitividade.

Vários estudos abordam, na atualidade, o advento de uma dessas formas de cooperação que se traduz nos chamados Parques Científicos e Tecnológicos. Esses modelos têm mostrado resultados positivos no âmbito internacional, tanto no que se refere às expectativas dos órgãos governamentais, coordenadores de políticas públicas, que têm como principal objetivo o desenvolvimento regional, bem como das empresas que a eles se associam.

De acordo com diversos autores (Parejo, 1992, Medeiros, 1996a, 1996b; Sanz, 1998; Spolidoro, 1997; Spolidoro, 1999), os parques científicos e tecnológicos podem ser considerados importantes instrumentos para o desenvolvimento regional e, de forma geral, apresentam as seguintes características:

São iniciativas componentes de políticas públicas para incentivo à inovação nas empresas; contribuem para o aumento da competitividade das empresas regionais ou em sua área de influência;

São iniciativas impulsionadoras para a criação de empresas inovadoras, intensivas em conhecimento e novas tecnologias, geralmente "spin-off" de instituições de pesquisa e ensino, que se situam nas proximidades;

São iniciativas com base em áreas físicas, onde as empresas inovadoras ou intensivas em conhecimento estão localizadas, que podem ser delimitadas ou disseminadas na cidade, tendência esta mais inovadora;

Promovem a interação dessas empresas com instituições de ensino, pesquisa, desenvolvimento tecnológico e de informação, localizadas em um campus de universidade ou em regiões que acumulam instituições dessa natureza;

Sociedade Industrial;

Auxiliam a evitar a degradação do tecido urbano, revitalizando antigas áreas resultantes do paradigma da

$>\quad$ Possuem uma entidade gestora para atuar como facilitadora nas questões imobiliárias, de entrosamento entre as empresas, para fins de divulgação, para estimular ações compartilhadas de obtenção de financiamentos, de gestão da infra-estrutura comum, de transferência de tecnologia, para estabelecimento de redes com outras iniciativas semelhantes, entre outras ações.

A formatação ou configuração de parques tecnológicos no Brasil, embora representem experiências muito jovens ou ainda em projeto ou em implantação, caracteriza-se por empresas que estão reunidas num mesmo local, dentro do campus da universidade, ao lado deste ou em uma área próxima. Existe uma entidade coordenadora concebida para facilitar a integração universidade-empresa e para gerenciar o uso das instalações existentes. Estão disponíveis, para venda ou locação, terrenos ou prédios, os quais abrigam uma incubadora ou condomínio de empresas.

No Brasil, pesquisas sobre a ocorrência deste fenômeno indicam a concepção do parque tecnológico como a forma mais completa de cooperação universidades/centros de pesquisa - empresa, pois concentra os seguintes benefícios (Medeiros, 1992; Medeiros, 1996a; Stal, 1998): a proximidade espacial entre todos os atores deste processo de cooperação; a presença de institutos de pesquisa e ensino; a aglomeração de empresas envolvidas diretamente com a tecnologia disponibilizada pelas instituições de pesquisa; a captação de projetos de inovação tecnológica conjuntos entre o setor privado e as instituições de pesquisa, resultantes de ações governamentais de caráter estratégico, visando o desenvolvimento local; a disponibilidade de uma estrutura organizacional, formal ou informal; a presença de incubadoras de empresas que dispõem de infra-estrutura física e administrativa bem como colocam à disposição dos incubados diversos serviços.

1 Dra. pela Universidade de São Paulo e Instituto de Pesquisas Energéticas e Nucleares, área de concentração: gestão da inovação tecnológica; M.Sc. em Engenharia Nuclear e Planejamento Energético pela Coordenação de Programas de Pós-Graduação (COPPE) da Universidade Federal do Rio de Janeiro (UFRJ); Bacharel em Física pela Universidade do Rio de Janeiro (UERJ).

Atualmente, atua como Chefe da Divisão de Inovação Tecnológica do Instituto de Pesquisas Energéticas e Nucleares. É consultora técnica do Centro Incubador de Empresas Tecnológicas - CIETEC e membro do Grupo Executivo para Desenvolvimento e Implantação do Parque Tecnológico de São Paulo.

Instituto de Pesquisas Energéticas e Nucleares - IPEN

Av. Prof. Lineu Prestes 2242, Cidade Universitária

CEP 05508-000 - São Paulo - SP Telefone/fax: (11) 38169151 e-mail: dmzouain@ipen.br 
Embora existam, na atualidade, muitos trabalhos sobre os parques científicos e tecnológicos, são observadas lacunas na literatura no que tange aos estudos e pesquisas sobre parques tecnológicos em centros urbanos ou em regiões metropolitanas, particularmente em países em desenvolvimento e no Brasil (as experiências e estudos são numerosos, neste tema, porém para clusters em municípios do interior ou em regiões fora dos grandes centros urbanos).

No contexto da cidade de São Paulo, em 1998 começaram a surgir no âmbito do Instituto de Pesquisas Energéticas e Nucleares (IPEN), do Instituto de Pesquisas Tecnológicas (IPT) e da Universidade de São Paulo (USP) discussões sobre a possibilidade de implantar um Parque Tecnológico na Cidade de São Paulo, nas cercanias da Cidade Universitária. Esta iniciativa se originou a partir do amadurecimento de algumas ações isoladas existentes Cidade Universitária tais como: a implantação do CIETEC (Centro Incubador de Empresas de Base Tecnológica), o projeto da Incubadora de Cooperativas Populares, a Incubadora de Empresas de Biotecnologia e a instalação de diversas associações setoriais. Associado a isto, estava o reconhecimento das mudanças que estão ocorrendo com relação à alteração da vocação econômica da cidade de São Paulo. A mudança física de empresas de grande porte de setores tradicionais, a alta taxa de desemprego e o mercado extremamente competitivo se tornaram desafios para a implementação de políticas públicas que possibilitassem a substituição de atividades declinantes por atividades nascentes, mais competitivas e que auxiliassem na atração de investimentos para a cidade.

A partir das discussões iniciais, essas entidades estruturaram uma proposta à Secretaria de Ciência, Tecnologia e Desenvolvimento Econômico e Turismo do Estado de São Paulo (SCTDET/SP) que consistia na implantação de um Parque Tecnológico como forma de contribuir com a política de atração de investimentos de qualidade; contribuir para a alteração da vocação econômica da região metropolitana de São Paulo; criar novas perspectivas para a revitalização urbana das cercanias da Cidade Universitária; intensificar a interação da Universidade e dos Institutos de Pesquisa localizados no campus com empresas criando uma motivação para a participação dos pesquisadores do campus; estimular a ampliação dos empreendimentos bem sucedidos a partir das incubadoras do campus; contribuir para o incremento de exportações com alto valor agregado; auxiliar na alteração do modelo "emprego" para "ocupação e renda".

A partir do reconhecimento dos pressupostos apresentados, a SCTDET/SP capitaneou esforços em torno de ações que visavam gerar um modelo de referência atualizado para parques tecnológicos urbanos.

Em decorrência da importância estratégica colocada sobre o tema, surge a idéia de desenvolver esta pesquisa, como forma de contribuir com a formulação de um modelo conceitual de parque tecnológico urbano bem como identificar e analisar experiências, preferencialmente já em implantação ou operação, nacionais e internacionais.

A presente pesquisa é dividida em duas fases: a primeira tem por objetivo construir um panorama de experiências nacionais e estrangeiras em parques tecnológicos, detalhando aspectos estratégicos, estruturais, gerenciais e operacionais, principais impactos e resultados, sendo analisadas sete experiências nacionais e três experiências internacionais previamente selecionadas e que concordaram em participar da pesquisa. A segunda parte caracteriza-se pelo desenvolvimento de um modelo conceitual de parque tecnológico para regiões urbanas adaptado aos requisitos da sociedade do conhecimento, sendo o mesmo, em seguida, particularizado para a região da cidade de São Paulo.

Neste artigo estarão sendo apresentados os resultados e comentários a respeito da primeira fase da pesquisa. A pesquisa completa foi desenvolvida por meio da Tese de Doutorado desta autora, defendida em maio de 2003, no Programa de Pós-Graduação Instituto de Pesquisas Energéticas e Nucleares (IPEN) em associação com a Universidade de São Paulo (USP).

\section{METODOLOGIA DA PESQUISA}

Para o desenvolvimento desta primeira fase dos trabalhos, foi gerado um instrumento de pesquisa aplicado às experiências selecionadas, tendo sido definidas as dimensões analisadas na pesquisa de campo. Na FIG. 1 são apresentadas as referidas dimensões. Com base nas dimensões definidas, um questionário foi elaborado em três versões: português, espanhol e inglês.

O questionário foi aplicado por meio da Internet, após obtida a concordância dos entrevistados para a participação na pesquisa. A aplicação do questionário foi acompanhada de uma série de explicações sobre a metodologia e a terminologia utilizada. Algumas dúvidas apresentadas pelos entrevistados foram respondidas por meio eletrônico. Em seguida, os questionários respondidos foram tabulados, tendo sido preparadas as entrevistas. As entrevistas e visitas foram realizadas contando com recursos financeiros da Fundação de Amparo à Pesquisa de São Paulo - FAPESP.

Para as experiências estrangeiras, principalmente Portugal e Espanha, os formulários, contatos e esclarecimentos foram todos feitos por meio eletrônico e telefone, tendo em vista a impossibilidade de realizar entrevistas pessoais. Quanto a Israel, a vinda de um especialista e pesquisador da área ao Brasil, também com o apoio da FAPESP, permitiu a realização da entrevista complementar.

\section{DISCUSSÃO E COMENTÁRIOS SOBRE OS RESULTADOS OBTIDOS}

Os resultados dessa primeira fase da pesquisa foram organizados em tabelas e matrizes, tendo sido obtidos a partir da aplicação do instrumento de pesquisa às experiências selecionadas, bem como aos estudos exploratórios realizados. São as seguintes as experiências analisadas: Pólo de Informática de São Leopoldo (RS), PADETEC - 
Parque de Desenvolvimento Tecnológico (CE), Porto Alegre Tecnópole (RS), Londrina Tecnópolis (PR), Porto Digital (PE), ) Pólo de Alta Tecnologia de Campinas (SP), Parque Tecnológico do Rio de Janeiro (RJ), Kiryat Weizmann Science Park (Israel), Parque Tecnológico de Andalucía S.A. (Espanha), TAGUSPARQUE S.A. (Portugal).

Para auxiliar na análise e identificar as práticas de sucesso, foi elaborada uma matriz lógica adaptada, acrescida da seleção das práticas de sucesso identificadas, para cada uma das experiências analisadas. Na TAB. 1 é apresentada a matriz de consolidação dos aspectos relevantes dos planos estratégicos identificados nas experiências analisadas. Esta prática contribuiu para a formulação dos aspectos estratégicos e de políticas públicas do modelo alvo da segunda fase desta pesquisa.

Na TAB. 2 são mostrados os aspectos ou práticas relevantes das experiências analisadas na pesquisa de campo. Na coluna de "resultado da apuração da pesquisa de campo" são levados em conta, nas opções com dados quantitativos, os aspectos que confirmaram a prática por número maior ou igual a 50\% entre os entrevistados, tendo sido descartados aqueles que não se manifestaram ou que não praticam os aspectos considerados. Na segunda coluna da TAB. 2 são apresentados a interpretação e os comentários, considerando também informações obtidas dos estudos exploratórios.

TABELA 1 - Matriz-Resumo das principais contribuições advindas da pesquisa de campo

\begin{tabular}{l|l}
\hline Objetivo & Apoiar políticas públicas (municipais, estaduais, federais) para o desenvolvimento regional, voltadas
\end{tabular} Superior $\quad$ para o avanço do conhecimento;

Criar novas ou transformar estruturas regionais (iniciativas "estruturantes") por meio da inovação tecnológica, articulando os vários atores (governo, academia, capital), proporcionando novos canais de relacionamento, comunicação e sinergia entre eles;

Identificar e promover maior visibilidade das vocações tecnológicas da região;

Desenvolver e recuperar áreas degradadas ou economicamente deprimidas, por meio da construção e sustentação de uma região classe mundial;

Ser um "núcleo de dinamização tecnológica" para as empresas da região.

\begin{tabular}{l|l} 
Objetivos & Gerar novos e melhores postos de trabalho na região;
\end{tabular}

Imediatos $\quad$ Estimular a criação de empresas de base tecnológica;

Buscar condiçães e instrumentos legais para estimular a instalação de empresas de base tecnológica na região;

Sedimentar e ampliar a interação empresa-universidade/centros de pesquisa, criando e fortalecendo mecanismos de apoio à inovação na empresa (fundos de apoio), bem como apoio legal à flexibilização das atividades de pesquisadores nas empresas;

Articular os agentes locais de inovação por meio de redes;

Disseminar a cultura do empreendedorismo;

Sensibilizar a comunidade e os formadores de opinião para as oportunidades geradas na Sociedade do Conhecimento;

Estimular as ações de incentivo às exportações de produtos e serviços com alto valor agregado;

Criar espaços físicos com características paisagísticas e ambientais bem cuidadas, que proporcionem lazer e bem estar às pessoas.

Produtos e $\quad$ Implantação e operação das iniciativas "estruturantes" (pólos, parques tecnológicos, tecnópoles, entre resultados $\quad$ outros);

esperados $\quad$ Maior oferta de empregos qualificados na região;

Aumento do número de empresas saudáveis, de base tecnológica, na região (micro, pequenas e médias, ou grandes empresas atraídas para a região);

Incremento no faturamento das empresas de base tecnológica da região;

Aumento das exportações de produtos com alto valor agregado;

Incremento de produtos inovadores no mercado por meio das empresas tecnológicas instaladas na região;

Incremento do número de patentes com alto valor comercial agregado;

Criação e ampliação das redes temáticas na região, bem como das alianças estratégicas e participação em programas internacionais;

Formação e qualificação de gestores para atuação nas estruturas criadas;

Incremento do número de (novos) empreendedores independentes;

Áreas urbanas revitalizadas, atrativas para outras atividades da economia (turismo, lazer, comércio, setor imobiliário);

Incremento das ações de sensibilização e animação para os projetos inovadores;

Pessoas felizes.

\begin{tabular}{l|l}
\hline Efeitos/ & Benefícios para a economia da região e do país;
\end{tabular}

impactos $\quad$ Maior divulgação (positiva) da região no país e no exterior (aumento do prestígio);

Recuperação de áreas públicas degradadas e subutilizadas;

Valorização de bairros e regiões; 


\begin{tabular}{|c|c|}
\hline & $\begin{array}{l}\text { Melhoria no movimento comercial da região; } \\
\text { Geração de tributos para o desenvolvimento de programas governamentais; } \\
\text { Melhoria das condições de vida da população da região; } \\
\text { Absorção da mão-de-obra local; } \\
\text { Aumento no percentual de sucesso das empresas no mercado; } \\
\text { Valorização da atividade acadêmica; } \\
\text { Melhoria no "parque industrial" local; } \\
\text { Estímulo à criação de outros projetos inovadores em outras regiões do país ("replicar" os modelos bem } \\
\text { sucedidos - "irradiar" os benefícios para o país); } \\
\text { Contribuição para a paz social. }\end{array}$ \\
\hline $\begin{array}{l}\text { Pressupostos } \\
\text { relevantes } \\
\text { para o êxito }\end{array}$ & $\begin{array}{l}\text { Articulação dos poderes públicos para o estabelecimento de políticas de incentivo à instalação de } \\
\text { empresas de base tecnológica na região; } \\
\text { Arcabouços legais em apoio às ações do projeto; } \\
\text { Estabelecimento de políticas de incentivo ao empreendedorismo nas universidades e centros de } \\
\text { pesquisa (cursos, disciplinas, treinamento, flexibilização da ação de pesquisadores nas empresas, } \\
\text { etc...); } \\
\text { Fortalecimento das parcerias com a iniciativa privada, captando o interesse para os projetos; } \\
\text { Fortalecimento e ampliação das relações internacionais; } \\
\text { Busca de suporte para os projetos por meio de fontes nacionais e internacionais, públicas e privadas; } \\
\text { Processo de seleção competente e criterioso de acordo com os objetivos estratégicos do projeto; } \\
\text { Contínuo desenvolvimento das ações de redes temáticas; } \\
\text { Benefícios claros para as universidades e centros de pesquisa de forma a estimular a sinergia entre os } \\
\text { atores do processo; } \\
\text { Plano de comunicação bem estruturado e pessoas atuantes para sensibilizar a comunidade local } \\
\text { (“ações de animação") bem como exportar a visão de sucesso do empreendimento; } \\
\text { Comunidade da região integrada ao projeto e consciente de seus benefícios. }\end{array}$ \\
\hline Bene & $\begin{array}{l}\text { Sócios ou associados ao empreendimento; } \\
\text { Comunidade empresarial local; } \\
\text { Comunidade técnico-científica que gravita em torno do projeto (não somente da região); } \\
\text { A economia da região e do país; } \\
\text { Poderes públicos e agências de fomento; } \\
\text { As pessoas da região. }\end{array}$ \\
\hline $\begin{array}{l}\text { Práticas de } \\
\text { Sucesso } \\
\text { Selecionadas }\end{array}$ & $\begin{array}{l}\text { Estrutura de legislação de apoio aos empreendimentos destacando-se: legislação referente à utilização } \\
\text { e posse de terrenos, sistema de incentivos fiscais (casos das experiências de São Leopoldo, Andalucia, } \\
\text { TAGUSPARK); Lei de Pesquisa\&Desenvolvimento e apoio ao empreendedorismo por intermédio do } \\
\text { Ministério da Indústria e Comércio (Departamento Cientista Chefe) - caso de Israel; } \\
\text { Ação de estímulo às pesquisas e empresas que trabalham com produtos inovadores que aproveitam as } \\
\text { riquezas da região - experiência do PADETEC do Ceará; } \\
\text { Cooperação técnica internacional bem articulada que traz amplos benefícios ao projeto: o exemplo do } \\
\text { Porto Alegre Tecnópole (com França e Espanha) e do PTA-Espanha (redes de cooperação } \\
\text { internacional); } \\
\text { O modelo do "Science Park Virtual" - serviços "on-line" para os associados - exemplo do TagusPark } \\
\text { em associação com outros parques da Alemanha, Finlândia e Grécia); } \\
\text { Sistema de "Plataformas" do Londrina Tecnópolis, decorrente de diagnóstico realizado na região alvo } \\
\text { do projeto que identificou as potencialidades e gargalos por setor da economia; } \\
\text { "Ações de Animação" do Londrina Tecnópolis, que mantém a comunidade informada e sensibilizada } \\
\text { para as ações do projeto; angaria as simpatias para as ações programadas; } \\
\text { Ações de articulação para a recuperação de uma área degradada e economicamente deprimida - o } \\
\text { exemplo do Porto Digital; } \\
\text { Articulação de atores para utilização do potencial econômico, científico e tecnológico de uma região - } \\
\text { o exemplo do Pólo de Alta Tecnologia de Campinas; } \\
\text { Valorização da atividade acadêmica e da vocação tecnológica da região contando com o apoio } \\
\text { institucional e político dos atores envolvidos - o exemplo do Parque Tecnológico de Rio de Janeiro. }\end{array}$ \\
\hline
\end{tabular}

TABELA 2 - Consolidação dos resultados da apuração da pesquisa de campo, interpretação e comentários - conclusão referente à pesquisa de campo

\begin{tabular}{l|c|c}
\hline Dimensão/aspecto & $\begin{array}{c}\text { Resultado da apuração da pesquisa de campo } \\
\text { - fatores considerados relevantes }\end{array}$ & Interpretação e comentários \\
\hline Localização & & \\
\hline Sistema ambiental & $100 \%$ das experiências analisadas declararam & Para a implantação de parques tecnológicos no \\
\hline
\end{tabular}




\begin{tabular}{|c|c|c|}
\hline Dimensão/aspecto & $\begin{array}{l}\text { Resultado da apuração da pesquisa de campo } \\
\text { - fatores considerados relevantes }\end{array}$ & Interpretação e comentários \\
\hline local & $\begin{array}{l}\text { que no Plano Estrutural (Diretor) consideram } \\
\text { o impacto ambiental na região. } \\
\text { Com relação à localização escolhida são } \\
\text { levados em conta, principalmente, fatores } \\
\text { relacionados a: } \\
\text {-Disponibilidade de acessos públicos a } \\
\text { espaços abertos - regiões de fácil acesso e de } \\
\text { baixa densidade de construções; } \\
\text {-A herança cultural da região. }\end{array}$ & $\begin{array}{l}\text { meio urbano os fatores relacionados à proteção } \\
\text { ambiental e melhoria/recuperação de áreas } \\
\text { devem ser considerados. As tendências atuais } \\
\text { mostram ser fundamental para um projeto deste } \\
\text { tipo que haja bons conhecimentos da região, } \\
\text { considerando-se os seguintes aspectos: } \\
\text { localização e acessos, geotecnia, normas para } \\
\text { meio ambiente (emissões gasosas, águas } \\
\text { residuais), entre outros fatores. }\end{array}$ \\
\hline $\begin{array}{l}\text { Arquitetura, Infra- } \\
\text { estrutura e } \\
\text { serviços }\end{array}$ & $\begin{array}{l}\text { São considerados fatores relevantes nos } \\
\text { projetos: } \\
\text { Acessos diretos a rodovias; } \\
\text { Acessos fáceis e rápidos a aeroportos; } \\
\text { Disponibilidade de transporte público (ônibus } \\
\text { municipal e intermunicipal, fretados); } \\
\text { Amplo estacionamento (a maior parte dos } \\
\text { entrevistados observa que acima de } 40 \% \text { do } \\
\text { pessoal do parque vai trabalhar com carro } \\
\text { próprio); } \\
\text { Plano de Urbanização priorizando: } \\
\text { planejamento do uso dos espaços, plano de } \\
\text { circulação, infra-estrutura de serviços } \\
\text { públicos, rede de comunicação; } \\
\text { Políticas claras quanto à negociação e cessão } \\
\text { de terrenos; } \\
\text { Ações programadas de controle arquitetônico }\end{array}$ & $\begin{array}{l}\text { A visão holística de atuação desses projetos, } \\
\text { principalmente quando localizados no meio } \\
\text { urbano, visa integrar as operações do parque à } \\
\text { vida da comunidade local, servindo também } \\
\text { como uma opção de lazer e cultura, e de } \\
\text { trabalho, auxiliando na formação de futuros } \\
\text { empreendedores e apoiando as políticas urbanas } \\
\text { implementadas pelo poder público. } \\
\text { Ressalta-se entre os elementos constitutivos dos } \\
\text { parques tecnológicos, além dos serviços } \\
\text { genéricos prestados à população que os } \\
\text { freqüenta, a existência, em alguns casos, de áreas } \\
\text { residenciais e serviços de apoio a estas áreas } \\
\text { (escolas, comércio), com o intuito de facilitar a } \\
\text { vida dos trabalhadores e freqüentadores do } \\
\text { parque, bem como proporcionar um movimento } \\
\text { e animação salutar na região. }\end{array}$ \\
\hline
\end{tabular}

e paisagístico;

Instalação de centros de serviços, lazer e

cultura para atender ao parque.

Contexto sócio-
econômico,
político e cultural

da região

\begin{tabular}{l|l|l}
\hline Informações & $50 \%$ das experiências analisadas estão & As informações demográficas obtidas confirmam \\
demográficas & localizadas em regiões metropolitanas criadas & o acerto na escolha das experiências analisadas, \\
& por lei; os outros 50\% estão na região de & uma vez que o foco da pesquisa reside em \\
influência de uma região metropolitana ou & modelos para regiões urbanas adensadas.. \\
\end{tabular}

urbana de média a densamente povoada;

$70 \%$ das experiências analisadas estão em áreas onde vivem de dois a até seis milhões de habitantes.

\begin{tabular}{l|l}
\hline Informações & As principais atividades econômicas \\
econômicas & influenciadas pelas ações do parque são: \\
& serviços e negócios $(70 \%) ;$ \\
por área de atuação: educação, treinamento, & convenções $(50 \%) ;$ tecnologia da informação, \\
& software, hardware, telecomunicações (40\%).
\end{tabular}

Os resultados apresentados refletem a mudança de orientação nas atividades econômicas das regiões urbanas ou metropolitanas.

As atividades culturais e de lazer (apesar de apenas mencionadas por duas das experiências analisadas), devem ser consideradas no modelo a ser desenvolvido, tendo em vista a estratégia de plena integração na sociedade local.

Estratégias de
desenvolvimento
regional

Existem políticas para suplantar barreiras culturais na região, com base em:

Desenvolvimento de parcerias locais (universidades, instituições de pesquisa, entre outros);

Desenvolvimento de uma linguagem comum, de dispositivos de comunicação, de ações comportamentais, entre outros fatores.

Em uma questão feita no instrumento, $80 \%$ dos entrevistados considera que a proximidade do parque a instituições de pesquisa e universidades traz benefícios para as empresas residentes. Em decorrência, o desenvolvimento de instrumentos de parceria com essas instituições torna-se fator de importância para obtenção de resultados positivos. A necessidade de investir na visibilidade do empreendimento também é 


\begin{tabular}{l|l|ll}
\hline Dimensão/aspecto & $\begin{array}{c}\text { Resultado da apuração da pesquisa de campo } \\
\text { - fatores considerados relevantes }\end{array}$ & \multicolumn{2}{|c}{ Interpretação e comentários } \\
\hline & & $\begin{array}{l}\text { considerada importante para o seu bom } \\
\text { desenvolvimento. }\end{array}$ \\
\hline Legislação de & & &
\end{tabular}

\section{apoio \\ Dispositivos}

legais em apoio ao projeto
$60 \%$ dos entrevistados informaram achar importante contar com dispositivos legais para apoio ao projeto;

Desses, $80 \%$ consideram fundamental a existência de dispositivos legais de incentivos para instalação de empresas ou isenção de impostos (dentre os que contam com esses dispositivos, as isenções mais comuns são de IPTU e de ISS) para empresas instaladas no pólo;

Desses, $50 \%$ contam ou consideram importante a existência de dispositivos legais para criação de pólos com doação ou cessão de terrenos, edificações ou outras estruturas e ordenação sobre uso do solo e planejamento urbano.

Modelo e estrutura

Objetivos estratégicos

Os objetivos estratégicos que foram classificados como "muito importantes" ou "importantes" (acima de 50\% somando-se as duas opções) são:

Apoio ao desenvolvimento regional;

Diversificação das atividades econômicas da região;

Desenvolvimento tecnológico da região;

Geração de empregos;

Disseminação do empreendedorismo;

Auto-sustentação do empreendimento.

compõem-se de estruturas organizacionais, entre elas: incubadoras de empresas, condomínios empresariais, empresas "âncoras", centros de pesquisa cooperativa empresas privadas de base tecnológica;

em alguns casos constituídos por leis municipais;

entidades civis sem fins lucrativos (o caso do Porto Digital é o único de OSCIP organização civil de interesse público) ou, nos casos da Espanha e Portugal são empresas (S. A.), ou gerenciados por empresas proprietárias do parque (caso de Israel). O caso do Parque Tecnológico do Rio de Janeiro é administrado pela UFRJ por meio das fundações de apoio.
O arcabouço legal para apoio ao projeto foi considerado, durante as entrevistas, como um fator determinante para o sucesso do empreendimento. Observou-se que algumas das experiências enfrentam problemas por falta de definições legais quanto a cessão ou arrendamento de terrenos e edificações.

Considera-se, entre os entrevistados, que o primeiro fator de atração dos empresários para instalação ou participação no desenvolvimento do projeto sejam os incentivos ou benefícios fiscais, muito embora reconheçam que a aproximação e facilidade de acesso a centros de ensino e pesquisa são fatores importantes para manutenção desses empresários.

De acordo com Fórmica (1997), o surgimento da indústria da inovação e dos chamados ecossistemas territoriais de inovação vêm sendo apontados como os campeões de concorrência global, partilhando a visão da nova era de "mercados e serviços" em detrimento da antiga "era de produção". As políticas públicas já privilegiam esta visão, com ações que têm sido direcionadas ao estímulo às exportações por meio da introdução da inovação nas empresas; entre elas encontram-se o apoio aos pólos, parques e incubadoras baseadas no conhecimento.

No que diz respeito aos modelos de parques tecnológicos e seus aspectos básicos, Vedovello (2000), quando menciona o relatório do European Innovation Monitoring System de 1996, apresenta dois modelos de parques e incubadoras tecnológicas, entre outros mistos, caracterizando-os segundo o seu foco de ação, a saber: aqueles que apresentam uma "estratégia universitária" e privilegiam, em seus modelos, o fortalecimento da interação universidadeempresa, sendo as ações coordenadas pela universidade; e aqueles que apresentam uma "estratégia regional", cujo foco de ação está voltado para o desenvolvimento regional e suas ações conseqüentes (geração de postos de trabalho, criação de empresas). Analisando sob esses aspectos, é possível identificar, entre as experiências focadas neste estudo, duas que podem ser enquadradas no primeiro modelo (PADETEC/CE; Parque Tecnológico do Rio de Janeiro); três podem ser enquadradas como um modelo misto (Pólo de Informática de São Leopoldo, Porto Digital e Pólo de Alta Tecnologia de Campinas) e as demais podem ser 


\begin{tabular}{|c|c|c|}
\hline Dimensão/aspecto & $\begin{array}{l}\text { Resultado da apuração da pesquisa de campo } \\
\text { - fatores considerados relevantes }\end{array}$ & Interpretação e comentários \\
\hline & & $\begin{array}{l}\text { enquadradas no segundo modelo (Porto Alegre } \\
\text { Tecnópole, Londrina Tecnópolis, Kiryat } \\
\text { Weizmann Science Park, Parque Tecnológico de } \\
\text { Andalucía, Tagusparque). }\end{array}$ \\
\hline \multicolumn{3}{|l|}{$\begin{array}{l}\text { Características de } \\
\text { gerenciamento }\end{array}$} \\
\hline Modelo de gestão & $\begin{array}{l}\text { As experiências analisadas apresentam as } \\
\text { seguintes estruturas organizacionais: } \\
\text { Conselho Gestor, síndico, Conselho Fiscal; } \\
\text { Conselho Diretor, Conselho Fiscal, } \\
\text { Superintendente; } \\
\text { Conselho Gestor, Comitê de Coordenação } \\
\text { (executor do projeto), Conselho Técnico- } \\
\text { Consultivo; de Administração, Diretoria } \\
\text { Conselho de } \\
\text { Executiva; } \\
\text { As experiências estrangeiras têm uma } \\
\text { configuração semelhante à de empresas: } \\
\text { Diretor geral, Diretor financeiro, Diretor } \\
\text { Comercial, Diretor de Operações, } \\
\text { Responsável por projetos (Espanha); } \\
\text { Conselho de Administração, Conselho } \\
\text { Científico e Tecnológico, Comissão Executiva } \\
\text { (Diretoria do Parque, Diretoria de } \\
\text { Planejamento, Diretoria de Operações, } \\
\text { Diretoria Administrativa e Financeira, Setor } \\
\text { de Relações Públicas e Apoio ao Residente) } \\
\text { (Portugal); } \\
\text { Gerente operacional, Gerente comercial } \\
\text { (Israel). }\end{array}$ & $\begin{array}{l}\text { As condições locais determinam a estrutura } \\
\text { possível para a gestão do projeto ou } \\
\text { empreendimento. Nos casos nacionais, no } \\
\text { entanto, os entrevistados consideram importante } \\
\text { a existência de um Conselho Superior com } \\
\text { representantes de todos os parceiros e principais } \\
\text { forças indutivas da comunidade, uma diretoria } \\
\text { ou gerência executiva e um órgão fiscal, como } \\
\text { estrutura básica. } \\
\text { As experiências estrangeiras espelham uma } \\
\text { realidade de estrutura de empresa. }\end{array}$ \\
\hline $\begin{array}{l}\text { Processo de } \\
\text { seleção e } \\
\text { acompanhamento }\end{array}$ & $\begin{array}{l}\text { Processos de seleção-modelos mencionados: } \\
\text { Formulários de inscrição e requisitos } \\
\text { veiculados pela INTERNET; não há edital; } \\
\text { propostas analisadas pelo conselho gestor; } \\
\text { Lançamento de edital, análise das propostas } \\
\text { por consultores ad-hoc, exame dos Planos de } \\
\text { Negócios, elaboração de parecer conclusivo, } \\
\text { aprovação do Conselho Diretor; } \\
\text { Em alguns casos, o processo de seleção é } \\
\text { aplicado somente para os candidatos para a } \\
\text { incubadora; } \\
\text { Edital e concorrência pública; } \\
\text { Com relação às experiências estrangeiras: não } \\
\text { há um processo formal de seleção; as } \\
\text { candidaturas são analisadas sob os aspectos } \\
\text { considerados relevantes dentro da política } \\
\text { desenvolvida para o empreendimento e } \\
\text { condições de disponibilidade e econômicas. } \\
\text { No caso de Portugal, a empresa efetua a } \\
\text { candidatura por impresso próprio, realiza a } \\
\text { entrevista, é analisada pelo Conselho } \\
\text { Científico e Tecnológico que envia o parecer } \\
\text { para a Comissão Executiva para as } \\
\text { providências de admissão da empresa. }\end{array}$ & $\begin{array}{l}\text { Admite-se para o desenvolvimento do modelo os } \\
\text { seguintes aspectos relevantes com relação a este } \\
\text { item: } \\
\text { Deve existir um processo de seleção oficializado, } \\
\text { com os requisitos bem definidos; } \\
\text { Deve existir a análise por parte de especialistas } \\
\text { ad-hoc ou na forma do Conselho Técnico- } \\
\text { Científico, como no caso da experiência } \\
\text { portuguesa, que garantam que a proposta está de } \\
\text { acordo com os princípios e objetivos do parque; } \\
\text { A apresentação de Plano de Negócio facilita a } \\
\text { análise da proposta, portanto deve haver um } \\
\text { modelo de Plano de Negócio; } \\
\text { O processo deve ser rápido e desburocratizado e, } \\
\text { de preferência, os requisitos e formulários devem } \\
\text { ser veiculados pela INTERNET. }\end{array}$ \\
\hline Parcerias e redes & $\begin{array}{l}\text { A maior parte das experiências nacionais são } \\
\text { associadas à ANPROTEC e também } \\
\text { desenvolvem cooperações com outras } \\
\text { entidades de acordo com as necessidades e } \\
\text { oportunidades que se apresentam. São }\end{array}$ & $\begin{array}{l}\text { A atuação em redes temáticas é considerada } \\
\text { importante para o desenvolvimento de iniciativas } \\
\text { estruturantes como os parques tecnológicos } \\
\text { sendo, portanto, considerada no modelo em } \\
\text { desenvolvimento. }\end{array}$ \\
\hline
\end{tabular}




\begin{tabular}{|c|c|c|}
\hline Dimensão/aspecto & $\begin{array}{l}\text { Resultado da apuração da pesquisa de campo } \\
\text { - fatores considerados relevantes }\end{array}$ & Interpretação e comentários \\
\hline & 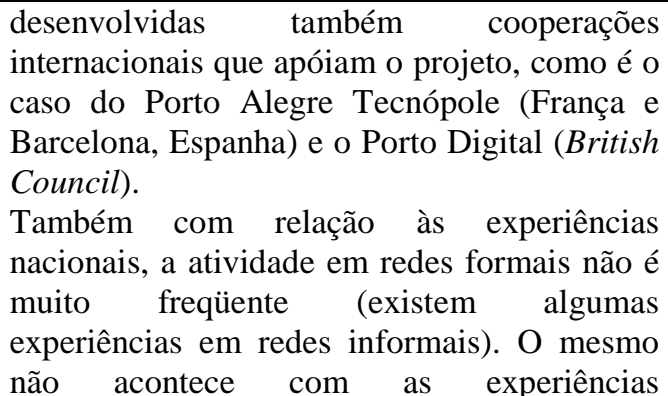 & $\begin{array}{l}\text { Os entrevistados, em sua maioria, consideram } \\
\text { que o estabelecimento de cooperações } \\
\text { internacionais traz ganhos positivos para o } \\
\text { desenvolvimento de iniciativas estruturantes, } \\
\text { principalmente os parques e pólos tecnológicos. } \\
\text { Destacam-se aqui os benefícios que foram } \\
\text { apresentados pela Porto Alegre Tecnópole em } \\
\text { sua cooperação com a França na área de projetos } \\
\text { de tecnópoles. }\end{array}$ \\
\hline
\end{tabular}

acontece com as exp internacionais onde, a participação em projetos e redes de cooperação, inclusive internacionais é comum a todas as experiências analisadas.

\begin{tabular}{l|l}
\hline Propriedade & Nas experiências nacionais, todos declararam
\end{tabular}
intelectual não haver uma política formalizada com relação aos aspectos de propriedade intelectual.

Já nas experiências internacionais foram observadas as seguintes situações:

Israel - o tema propriedade intelectual é tratado diretamente pelas empresas; a gestão do parque não interfere no processo, nem nas negociações sobre o assunto;

Parque de Andalucia - acontece o mesmo;

Tagusparque - faz parte de uma rede nacional de Gabinetes de Apoio à Propriedade Intelectual (GAPI), estando capacitado para internamente prestar apoio nesta área para as empresas.

\begin{tabular}{l}
\hline $\begin{array}{l}\text { Aspectos } \\
\text { financeiros }\end{array}$ \\
\hline Estratégias de \\
auto-sustentação
\end{tabular}

Das dez experiências analisadas, sete informaram a faixa de seus custos operacionais, ficando assim distribuídos: uma apresenta custo inferior a R\$ $100 \mathrm{mil} / \mathrm{ano}$; duas apresentam custo na faixa de $\mathrm{R} \$$ $101 \mathrm{mil}$ a R\$ 500 mil/ano; quatro apresentam custos superiores a $\mathrm{R} \$ 1$ milhão/ano, estando incluídas, neste caso, todas as experiências internacionais.

Dentre as experiências nacionais analisadas, cinco não consideram estratégias de total autosustentação.

Apenas quatro das experiências analisadas apresentaram estratégia de auto-sustentação, dentre elas encontram-se: o Porto Digital (a médio e longo prazos) e as experiências internacionais que, conforme as informações recebidas, já são auto-sustentáveis.

\begin{tabular}{l|l}
\hline $\begin{array}{l}\text { Marketing e } \\
\text { comunicação }\end{array}$ & \\
\hline $\begin{array}{l}\text { Ações de } \\
\text { sensibilização e } \\
\text { visibilidade }\end{array}$ & $\begin{array}{l}60 \% \text { das experiências analisadas informaram } \\
\text { não existir uma política de comunicação e } \\
\text { marketing para a região em apoio ao } \\
\text { empreendimento; algumas dessas experiências } \\
\text { desenvolvem ações isoladas. } \\
40 \% \text { das experiências analisadas informaram } \\
\text { existir uma política de comunicação e }\end{array}$ \\
\hline
\end{tabular}

O que se observa durante as entrevistas é que este aspecto não é, na maioria das vezes, considerado no escopo do planejamento do empreendimento, pelo menos com relação às experiências nacionais.

No caso do interesse desta pesquisa, a relação empresa-universidade/instituição de pesquisa é considerada importante para o sucesso do Parque como uma política pública de difusão do conhecimento e, em conseqüência, o tema propriedade intelectual/industrial deve ser desenvolvido no modelo. Com relação a este tema, a prática do Tagusparque parece ser a mais adequada, visto tratar-se de uma ação em rede que disponibiliza os serviços e benefícios para todos os seus nós.

As experiências internacionais, por estarem mais bem estruturadas, apresentam um orçamento de custeio definido.

Entre as estratégias de auto-sustentação encontram-se os seguintes mecanismos: recebimento de aluguéis e rendas (arrendatários), venda de espaços e terrenos para empresas; venda de serviços de consultoria - programas de formação e treinamento (inclusive com participação em programas nacionais e internacionais).
Embora a maior parte das experiências analisadas não possua uma política ou plano estruturado de comunicação e marketing, ações de sensibilização e de busca de visibilidade são desenvolvidas, entre elas destacam-se:

- Página na INTERNET com espaço para boletins com notícias sobre o 


\begin{tabular}{|c|c|c|}
\hline \multirow[t]{2}{*}{ Dimensão/aspecto } & $\begin{array}{l}\text { Resultado da apuração da pesquisa de campo } \\
\text { - fatores considerados relevantes }\end{array}$ & Interpretação e comentários \\
\hline & $\begin{array}{l}\text { marketing para a região em apoio ao } \\
\text { empreendimento. } 60 \% \text { das experiências } \\
\text { analisadas informaram não existir uma } \\
\text { política de comunicação e marketing para a } \\
\text { região em apoio ao empreendimento; algumas } \\
\text { dessas experiências desenvolvem ações } \\
\text { isoladas. } \\
40 \% \text { das experiências analisadas informaram } \\
\text { existir uma política de comunicação e } \\
\text { marketing para a região em apoio ao } \\
\text { empreendimento. }\end{array}$ & $\begin{array}{l}\text { empreendimento (jornal eletrônico); } \\
\text { Programas de animação e articulação } \\
\text { empresarial; } \\
\text { Ações organizadas junto a líderes } \\
\text { comunitários e formadores de opinião } \\
\text { da região. } \\
\text { Além dessas ações mais tradicionais, destacam- } \\
\text { se algumas práticas que estão ligadas a Planos } \\
\text { Estratégicos para as regiões de influência dos } \\
\text { empreendimentos (liderados por entidades } \\
\text { governamentais locais e associações de classes, } \\
\text { entre outros atores). Dentre essas práticas } \\
\text { destacam-se: } \\
\text { "Ações Tecnopolitanas" e participação em } \\
\text { programas internacionais de planejamento } \\
\text { urbano, social e de integração regional (Porto } \\
\text { Alegre Tecnópole); } \\
\text { Programas de animação e articulação } \\
\text { empresarial (ADETEC-Londrina Tecnópolis); } \\
\text { Selo Porto Digital; } \\
\text { Participação no Plano Estratégico para a Cidade } \\
\text { do Rio de Janeiro (Parque Tecnológico do Rio } \\
\text { de Janeiro); } \\
\text { "Portas Abertas" (Parque Tecnológico de } \\
\text { Andalucia). }\end{array}$ \\
\hline \multicolumn{3}{|l|}{$\begin{array}{l}\text { Formação e } \\
\text { treinamento }\end{array}$} \\
\hline $\begin{array}{l}\text { Ações de } \\
\text { formação e } \\
\text { treinamento de } \\
\text { pessoas }\end{array}$ & $\begin{array}{l}40 \% \text { desenvolvem ações de estímulo ao } \\
\text { empreendedorismo e gestão de negócios por } \\
\text { meio de treinamento; } \\
60 \% \text { não desenvolvem ações de estímulo ao } \\
\text { empreendedorismo e gestão de negócios por } \\
\text { meio de treinamento; } \\
\text { Desses } 60 \% \text { que não desenvolvem ações de } \\
\text { treinamento para o empreendedorismo e } \\
\text { gestão de negócios, 90\% utilizam o apoio de } \\
\text { entidades de ensino e outras entidades locais } \\
\text { ou regionais e estimulam a participação em } \\
\text { eventos e cursos ministrados por outras } \\
\text { organizações. } \\
\text { Com relação a cursos para a elaboração de } \\
\text { Planos de Negócios, apenas duas das } \\
\text { experiências, a de Portugal e a da Espanha, } \\
\text { proporcionam este tipo de treinamento para } \\
\text { seus associados. No caso do PADETEC, no } \\
\text { Ceará, utilizam os cursos do SEBRAE/CE } \\
\text { para este fim. }\end{array}$ & $\begin{array}{l}\text { A preocupação em estimular as ações de } \\
\text { treinamento em empreendedorismo e gestão de } \\
\text { negócios na região de influência das } \\
\text { experiências analisadas foi observada durante as } \\
\text { entrevistas e nas informações veiculadas, embora } \\
\text { a maior parte delas não atue diretamente na } \\
\text { estruturação de cursos e treinamento nesta área. } \\
\text { Pode-se observar a importância que é dada a este } \\
\text { tema visto que, entre as experiências, são } \\
\text { identificadas associações com organizações de } \\
\text { ensino e fomento para fins de treinamento e } \\
\text { estímulo à cultura do empreendedorismo, } \\
\text { acentuando o aspecto estratégico regional. } \\
\text { Com relação ao Plano de Negócios observou-se } \\
\text { que não existem ações específicas para apoiar os } \\
\text { associados neste sentido, exceto nos casos de } \\
\text { Portugal, Espanha e do Ceará. }\end{array}$ \\
\hline \multicolumn{3}{|l|}{$\begin{array}{l}\text { Resultados e } \\
\text { impactos na região }\end{array}$} \\
\hline $\begin{array}{l}\text { Impactos na } \\
\text { região }\end{array}$ & $\begin{array}{l}40 \% \text { das experiências analisadas declararam } \\
\text { não terem sido detectadas transformações } \\
\text { regionais ou terem sido detectados discretos } \\
\text { avanços nas atividades econômicas no âmbito } \\
\text { da zona de influência dos empreendimentos. } \\
60 \% \text { das experiências analisadas declararam } \\
\text { haver transformações regionais significativas } \\
\text { devido a projetos ou ações implantadas em } \\
\text { decorrência dos empreendimentos. }\end{array}$ & $\begin{array}{l}\text { As experiências analisadas, em sua maioria, não } \\
\text { dispõem de um conjunto de indicadores de } \\
\text { resultados ou de impactos regionais para } \\
\text { mensurar a influência dos empreendimentos no } \\
\text { desenvolvimento da região. A exceção das } \\
\text { experiências internacionais que possuem um } \\
\text { conjunto de indicadores de resultados bem } \\
\text { definidos, o levantamento dos resultados nas } \\
\text { demais experiências dependeu de esforços } \\
\text { adicionais de pesquisa para identificá-los. }\end{array}$ \\
\hline
\end{tabular}




\begin{tabular}{|c|c|c|}
\hline Dimensão/aspecto & $\begin{array}{l}\text { Resultado da apuração da pesquisa de campo } \\
\text { - fatores considerados relevantes }\end{array}$ & Interpretação e comentários \\
\hline $\begin{array}{l}\text { Principais } \\
\text { resultados }\end{array}$ & $\begin{array}{l}\begin{array}{l}\text { Entre os indicadores utilizados pelas } \\
\text { experiências } \\
\text { acompantrangeiras }\end{array} \\
\text { estão: } \\
\text { Número de empresas de base tecnológica } \\
\text { criadas; } \\
\text { Número de empregos diretos criados; } \\
\text { Faturamento total das empresas instaladas; } \\
\text { Número de empresas tecnológicas de médio e } \\
\text { grande portes atraídas para a região. } \\
\text { Entre os indicadores de impacto regional } \\
\text { (dados qualitativos) observados destacam-se: } \\
\text { Discreto avanço na atividade econômica local; } \\
\text { Identificação de regiões de potencial } \\
\text { tecnológico; } \\
\text { Captação de interesse e atração de instituições } \\
\text { e empresas baseadas no conhecimento; } \\
\text { Sensibilização do poder público e criação de } \\
\text { dispositivos de benefícios fiscais para atração } \\
\text { de empresas; } \\
\text { Melhoria da imagem da região em âmbito } \\
\text { nacional e internacional; } \\
\text { Transformação do tecido urbano (melhoria na } \\
\text { qualidade de infra-estrutura e de serviços). }\end{array}$ & $\begin{array}{l}\text { Os indicadores clássicos de resultados são } \\
\text { aplicados pelas experiências estrangeiras, o que } \\
\text { permite uma visibilidade do desenvolvimento } \\
\text { dos empreendimentos. Porém, essa visibilidade } \\
\text { não é medida, ou seja, não são respondidas } \\
\text { questões relativas ao grau de importância dos } \\
\text { empreendimentos para a vida da sociedade local } \\
\text { (comentada pela própria sociedade). Alguns } \\
\text { eventos de sensibilização são esporadicamente } \\
\text { realizados (como no caso de Portugal e Espanha) } \\
\text { porém, não foram mencionadas práticas } \\
\text { estabelecidas neste sentido. Para obtenção das } \\
\text { informações sobre os dados qualitativos } \\
\text { observou-se uma dificuldade adicional, pois não } \\
\text { estão estabelecidas práticas rotineiras de } \\
\text { identificação e medição de impactos regionais. }\end{array}$ \\
\hline
\end{tabular}

\section{COMENTÁRIOS FINAIS}

Este artigo teve por objetivo apresentar a primeira etapa de um estudo do fenômeno dos parques tecnológicos, visando gerar, na segunda fase da pesquisa, já realizada, um modelo conceitual atualizado para parques tecnológicos urbanos. Foram identificados, durante os estudos exploratórios da pesquisa, modelos regionais de parques tecnológicos, que caracterizam movimentos importantes e apresentam resultados sócio-econômicos relevantes para as regiões de influência, estando entre eles os modelos: californiano, o britânico, o norte-europeu e o mediterrâneo. Também destacou-se como uma tendência a formação de associações e redes regionais e internacionais de parques tecnológicos, podendo-se comentar, especialmente, o desenvolvimento deste movimento, nos últimos anos, nos países asiáticos. Um aspecto importante relaciona-se a formas encontradas pelos parques tecnológicos para permitir a internacionalização de empresas a eles associadas, principalmente pela formação de alianças estratégicas, promovendo a expansão de suas atividades e permitindo a criação de subsidiárias e escritórios regionais dessas empresas em outros países.

Os resultados do movimento de parques tecnológicos foram vistos por meio dos seus indicadores em termos mundiais, conforme as pesquisas da IASP (vide página na Internet: www.iasp.ws). Esses apontam para uma intensificação da criação de parques tecnológicos a partir da década de 90 e para uma tendência de crescimento do movimento no novo século. Os parques tecnológicos são geradores de empregos para a região em que atuam, principalmente para a mão-de-obra qualificada. Os números também indicam que $75 \%$ dos parques encontram-se em regiões urbanas, ou próximos a elas, sendo, porém, esta ocorrência relacionada, principalmente, a cidades pequenas, com até 500.000 habitantes; as experiências em cidades grandes (com mais de um milhão de habitantes) são ainda discretas. $\mathrm{O}$ fator proximidade com as instituições de pesquisa e ensino confirma-se como muito importante para os promotores dessas iniciativas, visto que a maior parte dos parques tecnológicos está muito próxima a campi universitários (76\%), sendo que $44 \%$ encontram-se localizados nos próprios campi; focalizando as relações entre as universidades e os parques, confirma-se o estabelecimento de um profícuo ambiente de fertilização cruzada visto que o número de ex-incubados e de "spin-off" nos parques vem crescendo nos últimos anos. Verifica-se que, nesse sentido, algumas universidades já preferem que seus escritórios de transferência e comercialização de tecnologia estejam situados nos parques tecnológicos (33\%), indicando uma busca pela aproximação com seus clientes potenciais.

Com relação ao movimento no Brasil, observou-se que, embora algumas iniciativas pioneiras tenham sido lançadas nas décadas de 80 e 90, o movimento de parques tecnológicos no Brasil é tardio. Estudos apontam para um crescimento do movimento no Brasil na década de 90, com tendência para uma expansão para os próximos anos, principalmente nas regiões sul e sudeste; grande parte do estímulo ao desenvolvimento desses modelos relaciona-se aos programas, incentivos e apoios, demonstrando uma crescente conscientização da necessidade de políticas e estratégias inovadoras baseadas no conhecimento, para o desenvolvimento regional e nacional.

Realizando um balanço entre os aspectos positivos e negativos dos parques tecnológicos, muito se fala dos benefícios sócio-econômicos regionais advindos dessas iniciativas, estando entre eles: a conscientização das 
comunidades para a importância do conhecimento, da tecnologia e da inovação para o desenvolvimento das regiões e das nações; a consolidação de modelos e metodologias para criação (e sucesso) de empresas baseadas no conhecimento; o desenvolvimento da cultura de atuação em redes e a formação de alianças estratégicas; os impactos positivos nas regiões de influência. No entanto, no contraponto, encontram-se aspectos negativos que têm sido observados no desenvolvimento desses modelos, estando entre eles: o apoio público aos parques tecnológicos por vezes onera e inibi a atuação e gestão dessas iniciativas, trazendo prejuízos ao desenvolvimento de seus processos, principalmente com relação ao estabelecimento de um ambiente informal e de sinergia entre pesquisadores e empresários; em algumas experiências, embora os resultados econômicos sejam positivos, a vinculação prática com as universidades e instituições de pesquisas da região é inferior ao desejável e, muitas vezes, insuficiente; ainda não estão bem desenvolvidas formas para captação de organizações ou iniciativas de capital semente e de capital de risco no ambiente dos parques tecnológicos.

Com relação à pesquisa de campo, cujos principais resultados foram apresentados neste texto, são feitos os seguintes comentários finais que contribuem para o processo de planejamento de projetos futuros:

- O Plano Diretor (ou estrutural) deve considerar o impacto ambiental na região de instalação do parque, principalmente sob os aspectos de proteção ambiental e melhoria ou recuperação de áreas degradadas;

- Os projetos arquitetônicos e a infra-estrutura de serviços devem conceituar uma visão holística, principalmente quando localizados no meio urbano, integrando as operações do Parque à vida da comunidade local, servindo também como uma opção de lazer e cultura, e de trabalho, auxiliando na formação de futuros empreendedores e apoiando as políticas urbanas implementadas pelo poder público; entre os elementos constitutivos dos parques tecnológicos, além dos serviços genéricos prestados à população que os freqüenta, devem existir, quando possível, áreas residenciais e serviços de apoio a estas áreas (escolas, comércio), com o intuito de facilitar a vida dos trabalhadores e freqüentadores do parque, bem como proporcionar um movimento e animação salutar na região;

- Possíveis barreiras culturais existentes na região podem ser suplantadas por meio do desenvolvimento de fortes parcerias locais e de uma linguagem comum, contando para isso com eficientes projetos de comunicação e de ações comportamentais; a necessidade de investir na visibilidade do parque é considerada importante para o seu bom desenvolvimento;

- $80 \%$ dos entrevistados consideraram que a proximidade do parque a instituições de pesquisa e universidades traz benefícios para as empresas residentes; em decorrência, o desenvolvimento de instrumentos de parceria com essas instituições torna-se fator de importância para obtenção de resultados positivos;

- O arcabouço legal para apoio ao projeto foi considerado fator determinante para o sucesso do empreendimento; algumas das experiências analisadas enfrentam problemas por falta de definições legais quanto à cessão ou arrendamento de terrenos e edificações; considera-se que o primeiro fator de atração dos empresários para participação no projeto sejam os incentivos ou benefícios fiscais, muito embora esses reconheçam que a aproximação e facilidade de acesso a centros de ensino e pesquisa são fatores importantes para sua manutenção e sucesso;

- Nos casos analisados, os modelos, em sua maioria, iniciam-se a partir de uma incubadora de empresas, compondo-se, em sua estrutura, além da incubadora: condomínios empresariais, empresas ou organizações "âncoras", centros de pesquisa, empresas privadas de base tecnológica; a forma de organização varia entre empresas constituídas; entidades sem fins lucrativos, organização social ou organização civil de interesse público; ou mesmo fazendo parte de universidade, sendo administrado por meio de fundações de apoio;

- Os modelos de gestão são variados, sendo que nos casos nacionais é considerada importante a existência de um Conselho Superior com representantes de todos os parceiros e principais forças indutivas da comunidade, uma diretoria ou gerência executiva e um órgão fiscal, como estrutura básica; as experiências estrangeiras espelham uma realidade de estrutura de empresa;

- A atuação em redes temáticas é considerada importante para o desenvolvimento dos parques tecnológicos; o estabelecimento de cooperações internacionais traz ganhos positivos para o desenvolvimento das iniciativas;

- A preocupação em estimular as ações de treinamento em empreendedorismo e gestão de negócios na região de influência das experiências analisadas foi observada durante as entrevistas e nas informações veiculadas, embora a maior parte delas não atue diretamente na estruturação de cursos e treinamento nesta área; pode-se observar a importância que é dada a este tema visto que, entre as experiências, são identificadas associações com organizações de ensino e fomento para fins de treinamento e estímulo à cultura do empreendedorismo, acentuando-se o aspecto estratégico regional;

- As experiências analisadas, em sua maioria, não dispõem de um conjunto de indicadores de resultados ou de impactos regionais para mensurar a influência dos empreendimentos no desenvolvimento da região; no entanto, indicadores clássicos de resultados são aplicados pelas experiências estrangeiras; observa-se que a visibilidade não é medida, ou seja, não existem evidências relativas ao grau de importância dos empreendimentos para a vida da sociedade local, comentada pela própria sociedade; não estão estabelecidas práticas rotineiras de identificação e medição de impactos regionais.

\section{BIBLIOGRAFIA}

ALBAGLI, S. Globalização e Espacialidade: o Novo Papel do Local.In: IBICT/MCT (Ed.). Globalização \& Inovação Localizada: Experiências de Sistemas Locais no MERCOSUL, Brasília: IBICT, 1999. 
CASSIOLATO, J. E., LASTRES, H.M.M. Inovação, Globalização e as novas Políticas de Desenvolvimento Industrial e Tecnológico.In: IBICT/MCT (Ed.). Globalização \& Inovação Localizada: Experiências de Sistemas Locais no MERCOSUL, Brasília: IBICT, 1999.

FORMICA, P. Atores inovadores do desenvolvimento econômico: empresas "acadêmicas" e universidades "empreendedoras" em ação nos ecossistemas territoriais e empresariais de inovação. In: GUEDES, M.; FORMICA, P. (Ed.) A economia dos parques tecnológicos. Rio de Janeiro: ANPROTEC, 1997.

MEDEIROS, J. A. Incubadoras de Empresas: Lições da Experiência Internacional. In: XIX SIMPÓSIO DE GESTÃO DA INOVAÇÃO TECNOLÓGICA, 1996, São Paulo. Anais... São Paulo: USP/PGT/FIA/PACTo, 1996 a.

MEDEIROS, J. A., MEDEIROS, L. A., MARTINS, T., PERILO, S. Pólos, Parques e Incubadoras - A Busca da Modernização e Competitividade. Brasília: CNPq/IBICT/SENAI, 1992.

MEDEIROS, J.A. Pólos científicos, tecnológicos e de modernização. TECBAHIA Revista Baiana de Tecnologia, v.11, n. 1, p. 11-25, 1996b.

MYERS, M.D. Qualitative Research in Information Systems. Disponível em: 〈http://www.auckland.ac.nz/msis/>. Acesso em 20 dez. 2002.

PAREJO, M., SANTOS, S. A. Parques Tecnológicos: uma análise comparativa de experiências consolidadas de países desenvolvidos. São Paulo: Universidade de São Paulo - Faculdade de Economia e Administração, 1992.

POPPER, K.R. A lógica da pesquisa científica. Tradução de Leônidas Hegenberg e Octanny Silveira da Mota. 2.ed. São Paulo: Editora Cultrix Ltda., 1974. Título original: The logic of scientific Discovery.

SALOMÃO, J. R. As Incubadoras de Empresas pelos seus Gerentes - Uma Coletânea de Artigos. Brasília: ANPROTEC, 1998.

SANZ, L. Parques científicos y tecnológicos: breve visión panorámica de sus modelos y tendencias In: VIII SEMINÁRIO DE PARQUES TECNOLÓGICOS E INCUBADORAS DE EMPRESAS. 1998, Belo Horizonte. Anais... Belo Horizonte: ANPROTEC, 1998.

SPOLIDORO, R. A sociedade do conhecimento e seus impactos no meio urbano. In: PALADINO, G.G.; MEDEIROS, L.A. (Org.) Parques tecnológicos e meio urbano: artigos e debates. Brasília: ANPROTEC, 1997.

SPOLIDORO, R. Habitats de inovação e empreendedores: agentes de transformação das estruturas sociais. TECHBAHIA Revista Baiana de Tecnologia, v. 14, n. 3, p. 9-21, 1999.

STAL, E. Cooperação Institucional Universidade-Empresa.In: SEBRAE/RS (Ed.) Série Tecnologia para a Competitividade. Porto Alegre: SEBRAE/RS, v. 2, 1998.

TERRA, J. C. C. Gestão do conhecimento: o grande desafio empresarial: uma abordagem baseada no aprendizado $e$ na criatividade. São Paulo: Negócio Editora, 2000.

THIOLLENT, M. Metodologia da pesquisa-ação. 11.ed. São Paulo: Cortez Editora, 2002.

VEDOVELLO, C. Aspectos relevantes de parques tecnológicos e incubadoras de empresas. Revista do BNDES, v. 7 , p.273-300, 2000.

ZOUAIN, D.M. Parques Tecnológicos - propondo um modelo conceitual para regiões urbanas - o Parque Tecnológico de São Paulo. 2003. Tese (Doutorado) - Instituto de pesquisas Energéticas e Nucleares - Universidade de São Paulo, São Paulo.

ZOUAIN, D.M., PLONSKI, G.A. Technology Park of Sao Paulo - building up a model to metropolitan regions of Sao Paulo State. In: $11^{\text {th }}$ INTERNATIONAL ASSOCIATION OF MANAGEMENT OF TECHNOLOGY (IAMOT) CONFERENCE. March 10-14, 2002. Miami Beach, Florida, USA.

ZOUAIN, D.M.; PLONSKI, G.A.; RODRIGUES, C.; ROGERO, J.R. Núcleo do Parque Tecnológico de São Paulo um "habitat" para promoção da inovação tecnológica na empresa. In: CONGRESSO ABIPTI 2002. 22-24 maio 2002. Curitiba, Paraná. Anais... Brasília: ABIPTI, 2002. CD-ROM.

ZOUAIN, D.M.; PLONSKI, G.A.; ROGERO, J.R. Parque Tecnológico de São Paulo - modelo de políticas públicas para aproximação de atores do sistema local de inovação. In: WORLD CONFERENCE ON BUSINESS INCUBATION - RIO 2001. October 23-26, 2001. Rio de Janeiro. Proceedings... Rio de Janeiro: COPPE/UFRJ/ANPROTEC/SEBRAE, 2001. CD-ROM.

ZOUAIN, D.M.; PLONSKI, G.A.; ROGERO, J.R.; VEDOVELLO, C. The technology park of São Paulo - a Project to stimulate the local knowledge-based innovation system. In: $4^{\text {th }}$ TRIPLE HELIX CONFERENCE. November 6-9, 2002. Copenhagen, Dinamarca. Proceedings... Copenhagen: The Triple Helix Conference Series, 2002.

ZOUAIN, D.M.; ROGERO, J.R.; PLONSKI, G.A. Parque Tecnológico de São Paulo - construindo um modelo para regiões metropolitanas. In: XXII SIMPÓSIO DE GESTÃO DA INOVAÇÃO TECNOLÓGICA. 6-8 nov. 2002. Salvador, Bahia. Anais...São Paulo: Núcleo de Política e Gestão Tecnológica da Universidade de São Paulo, 2002. CDROM. 


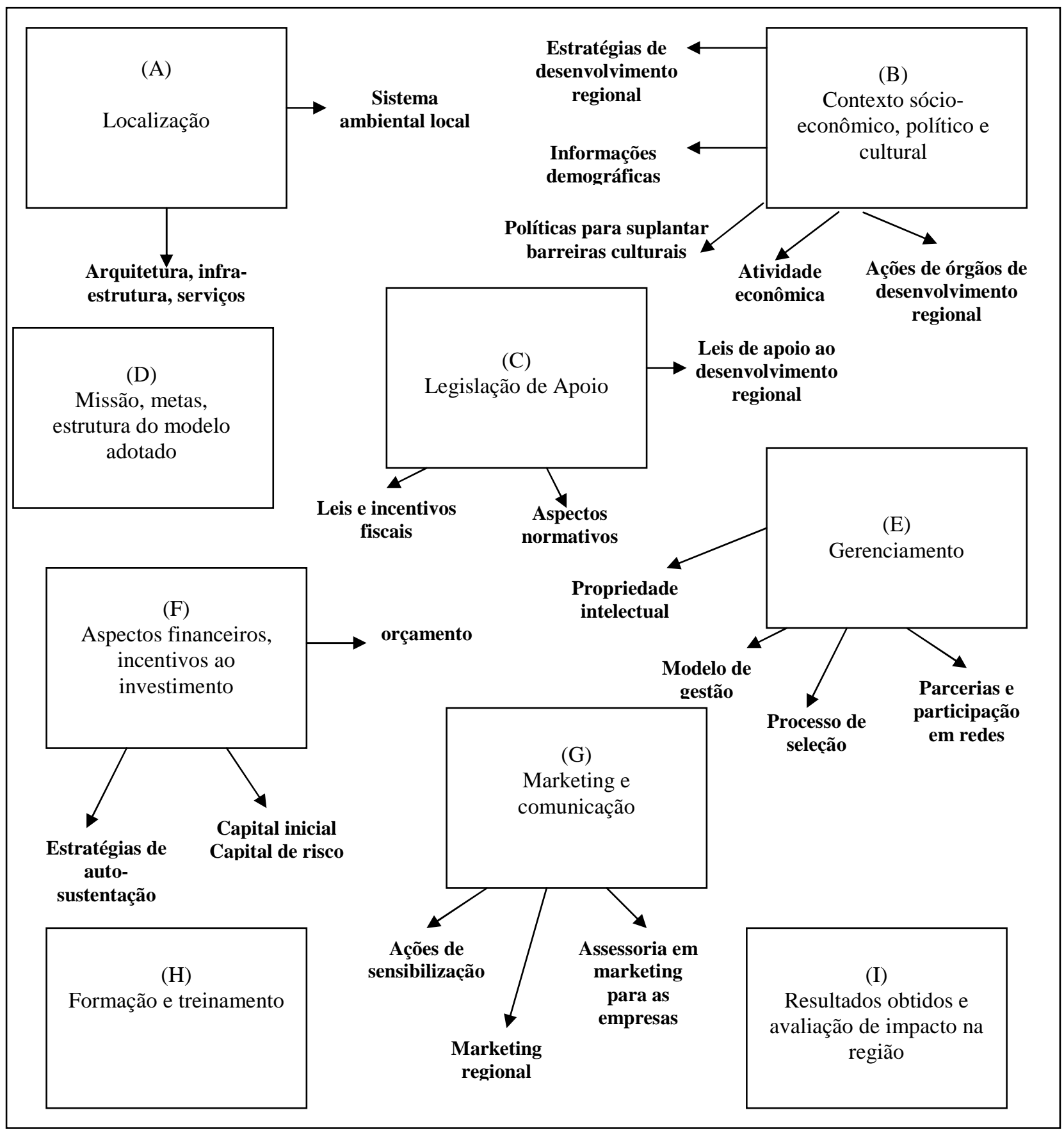

